07

\title{
Микротрещины в гетерогенном твердом теле (песчанике) при трении
}

\author{
(C) В.И. Веттегрень ${ }^{1,2}$, А.В. Пономарев ${ }^{2}$, Р.И. Мамалимов ${ }^{1,2}$, И.П. Щербаков ${ }^{1}$ \\ ${ }^{1}$ Физико-технический институт им. А.Ф. Иоффре РАН, \\ Санкт-Петербург, Россия \\ ${ }^{2}$ Институт ффизики Земли им. О.Ю. Шмидта РАН, \\ Москва, Россия \\ E-mail: Victor.Vettegren@mail.ioffe.ru
}

Поступила в Редакцию 11 марта 2019 г.

В окончательной редакции 11 марта 2019 г.

Принята к публикации 12 марта 2019 г.

При помощи триболюминесценции проведены исследования скорости роста и размеров микротрещин, образующихся в поверхностном слое гетерогенного природного твердого тела (песчаника) при трении. Найдено, что при разрушении кристаллических решеток плагиоклаза и кварца, входящих в состав песчаника, возникают сигналы триболюминесценции. Каждый сигнал соответствует микротрещине, поверхность которой содержит электронно-возбужденные свободные радикалы $\equiv \mathrm{Si}-\mathrm{O}^{-}$и ионы $\mathrm{Fe}^{3+}$. По скорости и времени роста интенсивности сигналов определены скорость роста и размеры микротрещин. Оказалось, что скорость роста микротрещин меньше скорости упругой волны $(\sim 700 \mathrm{~m} / \mathrm{s})$ и варьирует от $\sim 380$ до $\sim 650 \mathrm{~m} / \mathrm{s}$. Размеры микротрещин заключены в пределах от $\sim 4$ до $\sim 7 \mu \mathrm{m}$. Предполагается, что изменения скорости и размеров микротрещин вызваны вариацией величин барьеров, при прорыве которых возникают микротрещины.

Ключевые слова: скорость роста микротрещин, размеры микротрещин.

DOI: $10.21883 /$ FTT.2019.07.47844.413

\section{1. Введение}

Известно [1-5], что процесс разрушения металлов, кристаллов и полимеров под действием механического напряжения начинается с рождения, роста и объединения мельчайших „зародышевых“ трещин с размерами от $\sim 100 \mathrm{~nm}$ до нескольких $\mu \mathrm{m}[3,4]$. До последнего времени не была определена скорость роста таких трещин, поскольку отсутствовал метод, позволяющий ее измерять с наносекундным разрешением. Перспективным для решения этой проблемы является метод регистрации и анализа сигналов триболюминесценции (TL), возникающей при образовании микротрещин во время разрушения гетерогенных природных диэлектриков. Как показали исследования [6-13], этот метод позволяет наблюдать образование и рост микротрещин в гетерогенных природных материалах.

Цель настоящей работы - определение скорости роста и размеров „зародышевых“ микротрещин, образующихся при трении гетерогенного природного твердого тела - песчаника.

\section{2. Объект и методы исследования}

Образцы готовили из блоков штуфов рифейского песчаника полуострова Средний, расположенного на северном побережье Кольского полуострова. На рис. 1 показан фрагмент фотографии поверхности исследован- ного образца. Анализ таких фотографий [11] показал, что $\sim 80 \%$ vol. песчаника занимают кристаллы кварца и плагиоклаза, $\sim 15 \%$ vol. - гидрослюд и $\sim 5 \%$ vol. анатаза. Средние размеры кристаллов кварца и плагиоклаза $\approx 60 \mu \mathrm{m}[11]$.

Для решения поставленной задачи использовалась установка, описанная в [10]. Она состоит из вращающегося диска и прижатого к нему стержня из песчаника. Диаметр диска - $140 \mathrm{~mm}$, а стержня - $9.5 \mathrm{~mm}$. Конец стержня затачивали на точильном круге. Диаметр конца заточенного стержня $-2 \mathrm{~mm}$. Линейная скорость вращения диска, $V_{d}=26 \mathrm{~m} / \mathrm{s}$. При прижатии стержня к

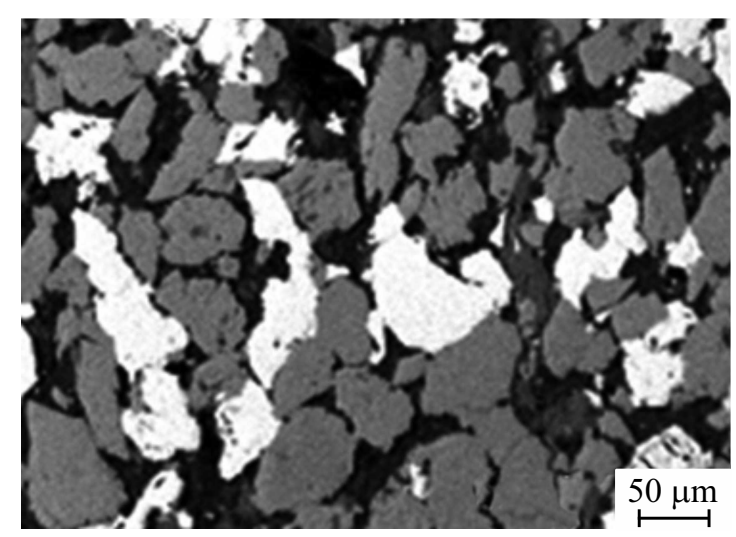

Рис. 1. Фотография поверхности исследованного образца песчаника. 
вращающемуся диску возникала TL. Излучение через кварцевый световод подавалось на поверхность фотоэлектронного умножителя РЕМ 136, а с него - на вход аналогово-цифрового преобразователя ADS-3112. Там сигналы TL оцифровывались и с временным разрешением 2 ns записывались в память компьютера для дальнейшей обработки и хранения.

Спектр TL регистрировали оптоволоконным спектрометром AvaSpec-ULSi2048L-USB2OE. Оказалось, что при трении песчаника связи $\mathrm{Si}-\mathrm{O}-\mathrm{Si}$ в кристаллических решетках кварца и плагиоклаза разрываются. После их разрыва образуются микротрещины, на берегах которых расположены возбужденные свободные радикалы $\equiv \mathrm{Si}-\mathrm{O}^{-}$и ионы $\mathrm{Fe}^{3+}$, замещающие ионы $\mathrm{Si}^{4+}$ в кристаллических ячейках плагиоклаза и кварца [10]. При релаксации возбуждения возникают сигналы TL [6-13].

Прежде чем перейти к изложению полученных результатов, нужно отметить, что, если давление стержня на вращающийся диск превышало $\sim 1 \mathrm{MPa}$, число сигналов люминесценции резко возрастало. В этих условиях они налагались друг на друга, что не позволяло исследовать каждый из них в отдельности. Поэтому описанные ниже результаты получены при давлении $1 \mathrm{MPa}$.

\section{3. Скорость образования и размеры микротрещин}

Фрагмент временной зависимости интенсивности сигналов TL при трении показан на рис. 2. Видно, что она имеет вид одиночных сигналов, которые состоят из 4 наложенных друг на друга максимумов (рис. 3). Каждый сигнал длился $\approx 25 \mathrm{~ns}$, а средняя величина временного интервала между ними на два порядка больше, $\approx 5 \mu \mathrm{s}$. Каждый из максимумов на рис. 3 соответствует микротрещине, на берегах которой располагаются электронно-возбужденные радикалы и ионы $[10,11]$. В та-

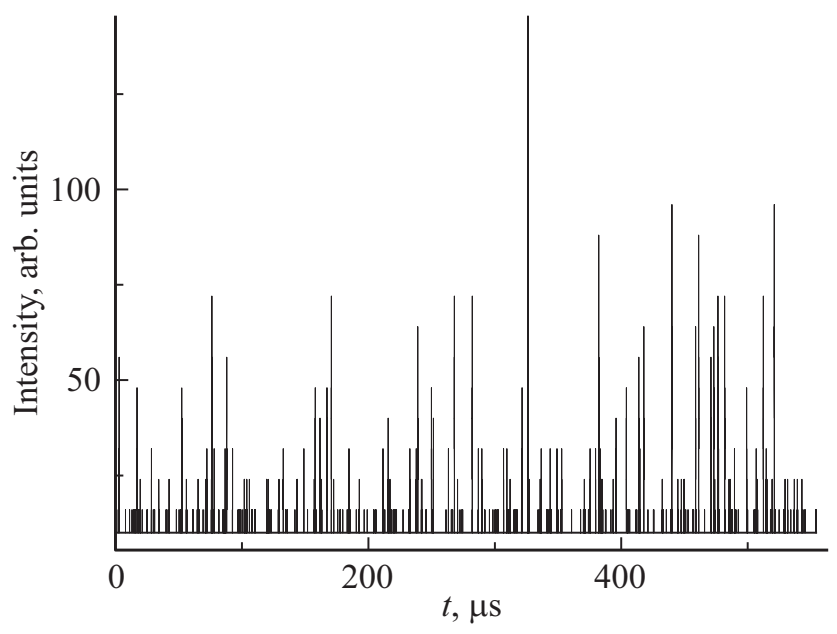

Pис. 2. Фрагменты временной зависимости TL при трении песчаника.

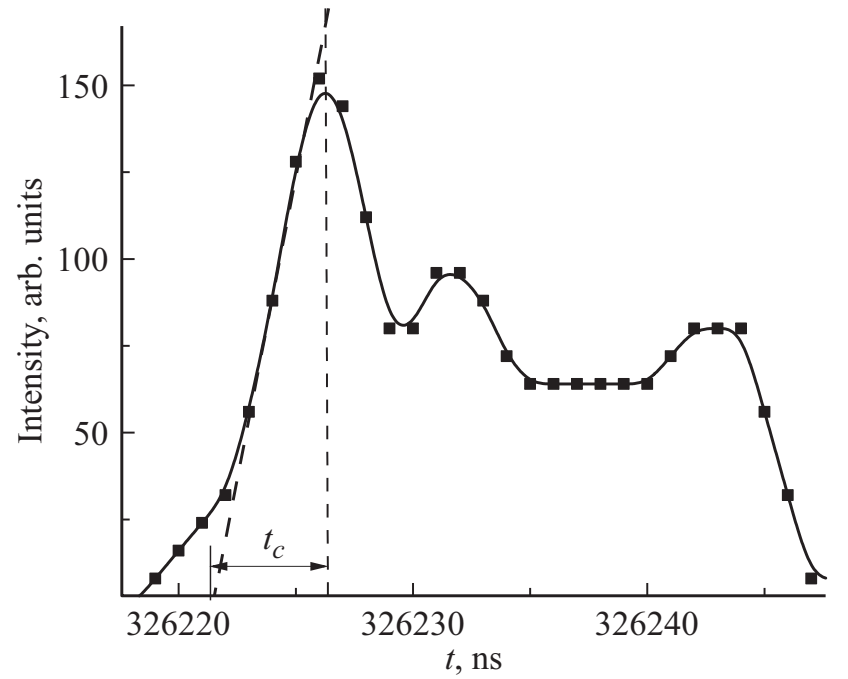

Рис. 3. „Одиночный“ сигнал TL при трении песчаника.

ком случае появление четырех максимумов в сигнале люминесценции показывает, что микротрещины формируются группами: по четыре микротрещины в каждой из них. Интенсивность второго, третьего и четвертого максимумов всегда была в $1.5-2.5$ раза меньше, чем первого. Она пропорциональна площади поверхности трещин [6-13]. Поэтому наблюдаемый вид сигнала показывает, что вслед за первой микротрещиной всегда образуется еще три микротрещины, причем каждая из них имеет площадь поверхности в $1.5-2.5$ раза меньше, чем первая. Вероятно, при образовании первой микротрещины напряжения около нее изменяются, что и приводит к появлению остальных трех микротрещин меньшего размера.

Рассмотрим более подробно временную зависимость интенсивности первого максимума. Она обусловлена временной зависимостью двух процессов. Первый рост интенсивности люминесценции при увеличении площади поверхности микротрещин. Второй - ее затухание после остановки микротрещины. Дифференцируя начальный участок максимума, можно найти максимальную скорость роста его интенсивности $d I / d t$, она пропорциональна максимальной скорости роста площади микротрещины $d S / d t$. Оказалось, что величина $d I / d t$ для разных сигналов, а значит, и скорость роста площади поверхности трещин, варьирует в несколько раз. Оценим ее.

На рис. 4 в полулогарифмических координатах приведено распределение скоростей сигналов люминесценции. Экспериментальные точки укладываются на прямую линию:

$$
\ln N=\ln N_{0}-b(d I / d t),
$$

где $N_{0}$ и $b$ - опытные параметры.

Экстраполируем эту линию к $\ln N=0$, и получим предельное значение $(d I / d t)_{\lim } \approx 24 \mu \mathrm{V} / \mathrm{ns}$ (см. рис. 4). Предположим, что это предельное значение скорости 


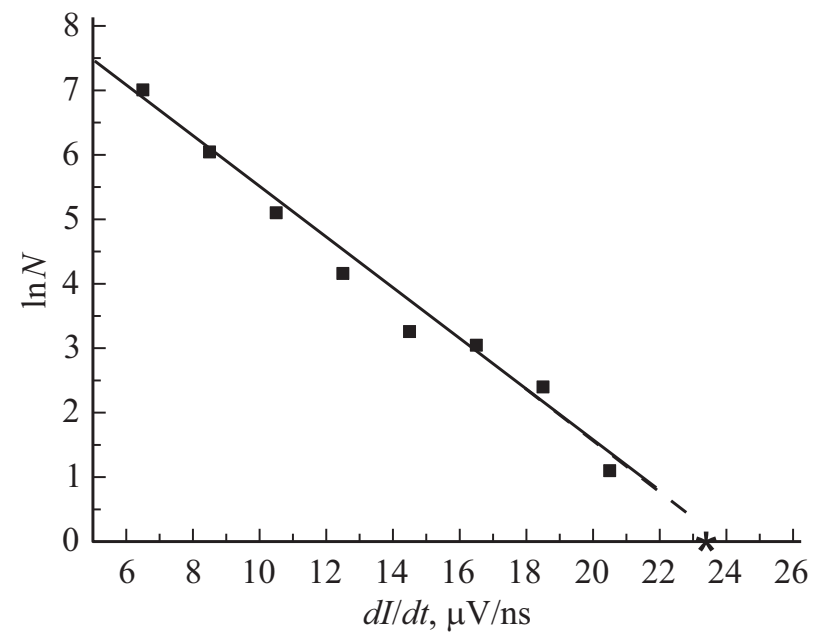

Рис. 4. Распределение скоростей роста интенсивности сигналов TL.

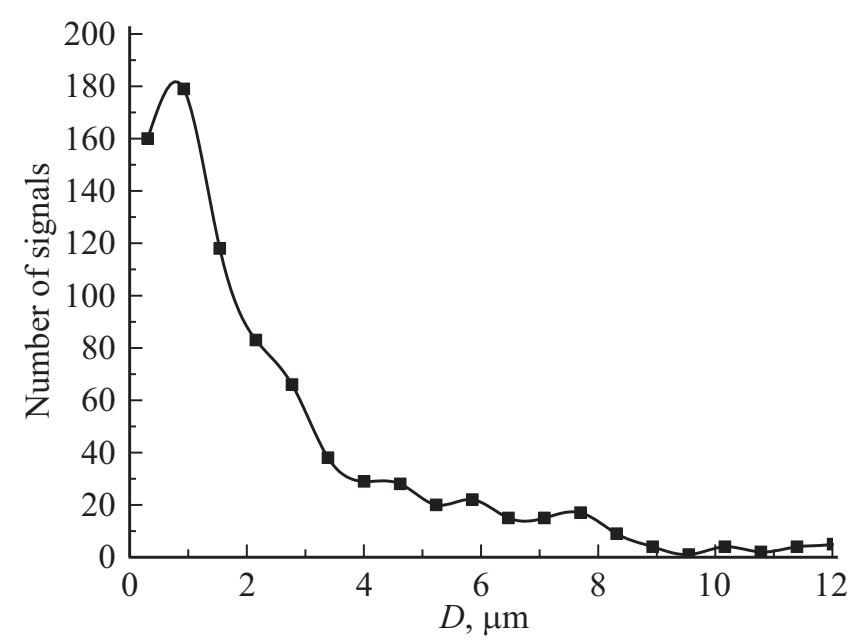

Рис. 5. Распределение расстояний между группами микротрещин.

роста сигналов TL соответствует скорости упругой волны $V_{e}$, которая для рифейского песчаника равна $\approx 700 \mathrm{~m} / \mathrm{s}$ [10]. Поскольку интенсивность сигнала люминесценции пропорциональна площади поверхности трещины, то скорость роста ее линейного размера $d L / d t$ можно вычислить как

$$
d L / d t=Q \sqrt{d I / d t}
$$

где $Q-$ коэффициент пропорциональности.

Тогда имеем следующее уравнение: $700 \mathrm{~nm} / \mathrm{ns} \approx Q(24 \mu \mathrm{V} / \mathrm{ns})^{1 / 2}$. Откуда получаем $Q \approx$ $\approx 143 \mathrm{~nm} /(\mu \mathrm{V} \cdot \mathrm{ns})^{1 / 2}$.

Используя это значение $Q$, можно определить скорость роста любых микротрещин в исследованном образце. Так, например, минимальное значение $d I / d t \approx 7 \mathrm{~V} / \mathrm{ns}$ (рис. 4) и, значит, минимальная скорость роста микротрещин, которая может быть зафиксиро- вана нашей установкой, $380 \mathrm{~m} / \mathrm{s}$. Максимальное значение $d I / d t \approx 20.5 \mu \mathrm{V} / \mathrm{ns}$ и максимальная скорость роста микротрещин $650 \mathrm{~nm} / \mathrm{ns}=650 \mathrm{~m} / \mathrm{s}$ - меньше скорости упругой волны.

Чем же вызвана широкая вариация скорости роста микротрещин? Известно [14-16], что микротрещины возникают при разрушении барьеров, препятствующих движению дислокаций по пересекающимся плоскостям скольжения. Скорость роста микротрещин определяется скоростью „сваливания“ дислокаций в трещину, которая, в свою очередь, задана локальными напряжениями в скоплениях дислокаций около барьеров. Чем больше величина барьера, тем больше скапливается около него дислокаций и тем больше скорость роста микротрещины. По-видимому, широкая вариация скорости роста микротрещин отражает вариацию величин барьеров.

Оценим время роста микротрещин. С этой целью проведем касательную к интенсивности, как показано на рис. 3. Продолжим ее до пересечений с осью времени и вертикальной прямой, проведенной через точку с максимальной интенсивностью $I_{m}$. Отрезок $t_{c}$ на оси времени будет приблизительно равен времени роста интенсивности сигнала люминесценции. Тогда размеры микротрещин, которые могут быть зарегистрированы нашей установкой, можно вычислить как $L=V_{c} t_{c}$. Оказалось, что самые мелкие микротрещины имеют размер приблизительно $4 \mu \mathrm{m}$, а наиболее крупные - приблизительно $7 \mu \mathrm{m}$.

Определим расстояния $D$ между группами микротрещин как: $D=V_{d} t_{d}$, где $t_{d}-$ интервал между сигналами TL. Вычисленное таким образом распределение расстояний показано на рис. 5. Видно, что величина $D$ изменяется от $\sim 0.3$ до $\sim 12 \mathrm{~mm}$. Наиболее вероятное расстояние между появлением микротрещин, $\sim 70 \mu \mathrm{m}$, близко к среднему размеру кристаллов кварца и плагиоклаза приблизительно $60 \mu \mathrm{m}$.

Вероятно, микротрещины рождаются в основном на границах между этими кристаллами. Действительно, известно, что наибольшее число дислокаций в кристаллах содержится в границах зерен или поверхности кристаллов [17].

\section{4. Заключение}

При трении гетерогенного нанокристаллического твердого тела - песчаника образуются микротрещины с линейными размерами от $\sim 4$ до $7 \mu \mathrm{m}$. Скорость их роста изменяется приблизительно в два раза и оказывается меньше скорости упругой волны.

\section{Конфликт интересов}

Авторы заявляют, что у них нет конфликта интересов. 


\section{Список литературы}

[1] В.Р. Регель, А.И. Слуцкер, Э.Е. Томашевский. Кинетическая природа прочности твердых тел. Наука, М. (1974). $560 \mathrm{c}$.

[2] В.И. Бетехтин, А.Г. Кадомцев. ФТТ 47, 5, 801 (2005).

[3] В.П. Тамуж, В.С. Куксенко. Микромеханика разрушения полимерных материалов. Зинатне, Рига. (1978). 294 с.

[4] В.А. Петров, А.Я. Башкарев, В.И. Веттегрень. Физические основы прогнозирования долговечности конструкционных материалов. Политехника, СПб. (1993). 475 с.

[5] П.Г. Черемской, В.В. Слезов, В.И. Бетехтин. Поры в твердом теле. Энергоатомиздат, М. (1990). 376 с.

[6] В.И. Веттегрень, В.С. Куксенко, И.П. Щербаков. ЖТФ 81, 4, 148 (2011).

[7] В.И. Веттегрень, В.С. Куксенко, Р.И. Мамалимов, И.П. Щербаков. Физика Земли 5, 58 (2012).

[8] В.И. Веттегрень, В.С. Куксенко, И.П. Щербаков. ФТТ 54, 7, 1342 (2012).

[9] В.И. Веттегрень, В.С. Куксенко, И.П. Щербаков. Физика Земли 5, 134 (2016).

[10] В.И. Веттегрень, Г.А. Соболев, А.В. Пономарев, И.П. Щербаков, Р.И. Мамалимов ФТТ 59, 931 (2017).

[11] В.И. Веттегрень, А.В. Пономарев, И.П. Щербаков, Р.И. Мамалимов. ФТТ 59, 1557 (2017).

[12] В.И. Веттегрень, А.В. Пономарев, И.П. Щербаков, Р.И. Мамалимов. ФТТ 59, 2263 (2017).

[13] В.И. Веттегрень, А.В. Пономарев, К. Arora, Haris Raza, Р.И. Мамалимов, И.П. Щербаков, И.В. Фокин. ФТТ 60, 2266 (2018).

[14] A.N. Stroh. Adv. Phys. 6, 6, 418 (1957).

[15] A.H. Cottrell. Theory of Crystal Dislocations. Gordon and Breach, NY. (1964). 91 p.

[16] В.И. Владимиров. Физическая природа разрушения металлов. Металлургия, М. (1984). 280 с.

[17] G. Gottstein. Physical Foundations of Materials Science. Springer, Berlin, Heidelberg (2004). 502 p.

Редактор Е.Ю. Флегонтова 